\title{
Multitasking in the Olfactory System: Context-Dependent Responses to Odors Reveal Dual GABA-Regulated Coding Mechanisms in Single Olfactory Projection Neurons
}

\author{
Thomas A. Christensen, Brian R. Waldrop, and John G. Hildebrand \\ Arizona Research Laboratories, Division of Neurobiology, University of Arizona, Tucson, Arizona 85721
}

Studies of olfaction have focused mainly on neural processing of information about the chemistry of odors, but olfactory stimuli have other properties that also affect central responses and thus influence behavior. In moths, continuous and intermittent stimulation with the same odor evokes two distinct flight behaviors, but the neural basis of this differential response is unknown. Here we show that certain projection neurons (PNs) in the primary olfactory center in the brain give contextdependent responses to a specific odor blend, and these responses are shaped in several ways by a bicuculline-sensitive GABA receptor. Pharmacological dissection of $P N$ responses reveals that bicuculline blocks $\mathrm{GABA}_{\mathrm{A}}$-type receptors/chloride channels in PNs, and that these receptors play a critical role in shaping the responses of these glomerular output neurons. The firing patterns of PNs are not odor-specific but are strongly modulated by the temporal pattern of the odor stimulus. Brief repetitive odor pulses evoke fast inhibitory potentials, followed by discrete bursts of action potentials that are phase-locked to the pulses. In contrast, the response to a single prolonged stimulus with the same odor is a series of slow oscillations underlying irregular firing. Bicuculline disrupts the timing of both types of responses, suggesting that $\mathrm{GABA}_{\mathrm{A}}$-like receptors underlie both coding mechanisms. These results suggest that glomerular output neurons could use more than one coding scheme to represent a single olfactory stimulus. Moreover, these context-dependent odor responses encode information about both the chemical composition and the temporal pattern of the odor signal. Together with behavioral evidence, these findings suggest that context-dependent odor responses evoke different perceptions in the brain that provide the animal with important information about the spatiotemporal variations that occur in natural odor plumes.

Key words: information coding; intermittency; GABA receptors; oscillations; olfaction; insect; moth; Manduca sexta
Olfactory glomeruli have long been suspected of playing a major role in processing information about the molecular features of odor stimuli (Adrian, 1950; Mori and Yoshihara, 1995; Hildebrand and Shepherd, 1997), and mounting evidence supports the concept of a glomerulus as a distinct spatial "address" in the brain for the representation of a particular type of odor ligand (Axel, 1995; Buck, 1996; Mombaerts et al., 1996). In contrast, the coding of stimulus features other than those related to the chemical composition of the odor has received relatively little attention. For example, natural olfactory stimuli possess a fine-scale structure, and the behavior of many animals is influenced by changes in the spatiotemporal properties of a meandering odor plume (Dethier, 1987; Murlis, 1997). Behavioral evidence from both aquatic (Moore, 1994; Atema, 1995) and terrestrial invertebrates (Willis and Baker, 1984; Vickers and Baker, 1992, 1994; MafraNeto and Cardé, 1994) shows, moreover, that these animals often cannot locate the source of an odor unless the stimulus is intermittent. Male moths perform stereotyped "zig-zagging" flight maneuvers that may further contribute to their intermittent re-

\footnotetext{
Received March 13, 1998; revised May 14, 1998; accepted May 15, 1998.

This work was supported by National Institutes of Health Grants AI-23253 and DC-02751 (J.G.H.). We thank Drs. Neil Vickers and Mark Willis for insightful discussions and suggestions on this manuscript, Charles Hedgcock for photographic assistance, and Dr. A. A. Osman for rearing Manduca sexta.

Correspondence should be addressed to Dr. T. A. Christensen, Arizona Research Laboratories, Division of Neurobiology, University of Arizona, P.O. Box 210077, Tucson, AZ 85721-0077.

Dr. Waldrop's present address: College of Arts and Sciences, University of Oklahoma, 429 Physical Sciences Building, Norman, OK 73019.

Copyright (C) 1998 Society for Neuroscience $\quad 0270-6474 / 98 / 185999-10 \$ 05.00 / 0$
}

ception of the sex pheromone released by a "calling" female (for review, see Cardé and Minks, 1997). Mammals also use active sampling strategies (e.g., sniffing) that impose on the sensory epithelium a distinct temporal pattern of odor stimulation, and different odorants or changes in odor concentration can evoke different patterns of sniffing (Youngentob et al., 1987). Thus, when the brain first detects an olfactory stimulus, the initial representation of the odor is often intermittent. Because numerous environmental factors can influence the temporal patterns of impulse activity in olfactory receptor cells, it can be expected that neural circuits in the primary olfactory center in the brain can encode or even accentuate these temporal patterns to preserve the quality of the olfactory information available for higher processing.

The nature of the processing codes used by neural circuits in the brain has been debated for many years (for review, see Hopfield, 1996; König et al., 1996; de Ruyter van Steveninck et al., 1997), and this discussion has included the mechanisms by which odors are discriminated in the olfactory system (Adrian, 1942; Haberly, 1985; Gelperin et al., 1996; Laurent, 1996). Such a code may use the average rate of firing to represent a stimulus, or alternatively, the precise sequence of action potentials may underlie a temporal code for odor information, often involving oscillations in membrane potential that tend to synchronize network activity (for review, see Bullock, 1997). In either case, the patterns of action potentials tend to be temporally complex. Intracellular analysis of mitral/tufted cells in vertebrates and the analogous projection neurons (PNs) in insects has indeed revealed complex responses to odor stimulation, including both 
depolarizing and hyperpolarizing potentials that produce temporally dynamic spike trains (Hamilton and Kauer, 1989; Kanzaki et al., 1989; Wellis et al., 1989; Christensen et al., 1993, 1996; Mori and Yoshihara, 1995; Laurent, 1996).

In this study, we investigated the integration of EPSPs and IPSPs in olfactory PNs of the sphinx moth Manduca sexta in the production of such patterned responses and examined the effects of these inputs on the spike code used by these glomerular output neurons. Most, if not all, of the $\sim 360$ wide-field local interneurons (LNs), with arborizations in most or all of the glomeruli in the antennal (olfactory) lobe, stain with antibodies against GABA (Hoskins et al., 1986; Distler, 1990; Homberg, 1990; Malun, 1991; Leitch and Laurent, 1996), and spike-triggered averaging and cross-correlation analyses of LN-PN paired recordings show that the LNs are the primary source of synaptic inhibition to PNs (see Fig. 1A) (Christensen et al., 1993, 1996; MacLeod and Laurent, 1996). Here, we present evidence that changes in the temporal pattern of an odor stimulus have a direct impact on the GABAregulated response patterns of PNs. Our findings also suggest that a single PN may use different coding mechanisms according to the particular environmental context in which the odor is presented. Both the fast IPSPs that modulate responses to rapid changes in odor concentration as well as the slower oscillations that emerge only under conditions of continuous stimulation are regulated by a bicuculline-sensitive $\mathrm{GABA}_{\mathrm{A}}$-type receptor on the dendrites of the PNs.

A preliminary report of some of this work appeared elsewhere (Christensen et al., 1998).

\section{MATERIALS AND METHODS}

Animals. M. sexta were reared from eggs on an artificial diet, as described previously (Christensen and Hildebrand, 1987), and dissected and prepared for intracellular recording by established procedures (Waldrop et al., 1987; Hansson et al., 1991; Christensen et al., 1993). After the antennal lobe (AL) had been desheathed with fine forceps, the preparation was superfused continuously $(1-2 \mathrm{ml} / \mathrm{min})$ with a physiological saline solution containing (in $\mathrm{mm}$ ): $150 \mathrm{NaCl}, 3 \mathrm{CaCl}_{2}, 3 \mathrm{KCl}, 10$ $\mathrm{N}$-tris[hydroxymethyl]methyl-2-aminoethanesulfonic acid buffer, and 25 sucrose, pH 6.9 (Christensen et al., 1993). Intracellular recordings were obtained from coarse neurites in the glomerular neuropil in which synaptic potentials are readily detectable and responsive to injected current.

Stimulation and recording. Silver wire hook electrodes placed under the antennal nerve were used for electrical stimulation of antennal sensory axons, which provided a convenient and controlled stimulus for the characterization of postsynaptic potentials in LNs and PNs. Electrophysiological data were recorded and stored on magnetic tape for off-line analysis. Data were digitized and analyzed with AxoScope software (Axon Instruments, Foster City, CA) or with Experimenter's Workbench (DataWave Technologies, Longmont, CO). Electrodes were filled with one of the following: $3 \mathrm{M} \mathrm{KCl}$ for chloride injection experiments; $2 \mathrm{M}$ $\mathrm{K}$-acetate for most recordings; or $4 \%$ (w/v) Lucifer yellow $\mathrm{CH}$ in water to examine the morphology of some neurons after injection with 10 $\mathrm{nA} / \mathrm{min}$ negative current. Histology and viewing of stained neurons followed standard procedures (Christensen et al., 1993). The odor stimulus used in all experiments was the natural sex pheromone obtained by rinsing a single female moth's pheromone gland with $n$-hexane (Tumlinson et al., 1989). Odor stimuli were prepared and delivered as described previously (Christensen et al., 1993), and the timing of the stimulus pulses was controlled via a computerized stimulator running customized ASYST scientific software (Keithly Instruments, Rochester, NY), as published previously (Waldrop and Hildebrand, 1989).

Multibarreled microinjection system. An array of seven independently regulated glass pressure pipettes $(1.5 \mathrm{~mm}$ outer diameter, $0.7 \mathrm{~mm}$ inner diameter; Frederick Haer, Brunswick, ME) was used for focal pressure ejection of GABA, ACh, and other compounds into the neuropil (Waldrop and Hildebrand, 1989). The pipette tips were dipped in cyanoacrylate adhesive to prevent uneven breakage of the barrels, and the final tip diameter measured 50-60 $\mu \mathrm{m}$ for all seven barrels. All compounds were dissolved in physiological saline and prepared daily or stored at $4^{\circ} \mathrm{C}$ for 1-2 d. Final concentrations inside the pipette were as follows: 1-100 mM GABA and ACh; 1-100 $\mu \mathrm{M}$ bicuculline methiodide (BMI); and 1-100 mM muscimol, baclofen, and cis-4-aminocrotonic acid (CACA). All of these agents were obtained from Sigma (St. Louis, MO) or Research Biochemicals (Natick, MA). One barrel of the seven-barrel array was always reserved for a saline control to check for mechanical effects. These were minimal as long as the pressure pipette array was situated at least $100 \mu \mathrm{m}$ from the intracellular microelectrode. In all experiments, the pressure pipette array was situated in the neuropil and fixed in position first, allowing for stable intracellular recordings for up to $45 \mathrm{~min}$.

\section{RESULTS}

\section{Orthodromic stimulation of the antennal nerve evokes a triphasic response in olfactory PNs}

Olfactory PNs in the moth AL were readily identified on the basis of their characteristic triphasic (inhibition-excitation-inhibition) response to brief electrical shocks of the antennal nerve (Christensen et al., 1996) (Fig. 1B). Stimulation of the ipsilateral antenna with an appropriate odorant (or odor blend) evokes the same basic pattern of activity in males and females (Christensen et al., 1993; King et al., 1997; Selchow et al., 1997). In males, it has been shown that the firing patterns of certain PNs that innervate the male-specific macroglomerular complex (MGC) can be tightly time-locked to the stimulus (Fig. $1 C$ ), even if the stimulus is a randomized series of odor pulses of varying duration (Christensen and Hildebrand, 1997). One purpose of this study was to investigate the pharmacology of the synaptic receptors that underlie the triphasic response and the tightly stimulus-locked responses of these PNs, the glomerular output neurons. The triphasic response consists of a rapid-onset hyperpolarizing IPSP $\left(\mathrm{I}_{1}\right)$, followed by a depolarizing EPSP, which generally gives rise to one or more action potentials. Another hyperpolarizing phase $\left(\mathrm{I}_{2}\right)$ follows $\mathrm{I}_{1}$ and the EPSP and can prevent the PN from firing for several seconds (Fig. $2 A$ ).

Several different pharmacological manipulations, involving both ion substitution tests and pressure ejection of GABA and related compounds, showed that the $\mathrm{I}_{1}$ phase could be mimicked by delivery of a pulse of GABA into the glomerular neuropil (see below), was mediated by an increased conductance to chloride ions (Fig. 2C), and was reversibly blocked by bicuculline, an antagonist of vertebrate $\mathrm{GABA}_{\mathrm{A}}$ receptors (Waldrop et al., 1987) (Fig. $1 B$ ). In contrast, the later $\mathrm{I}_{2}$ phase was insensitive to changes in external or internal chloride concentration (Fig. 2C) and exhibited a reversal potential with a mean value nearly $10 \mathrm{mV}$ below that for $\mathrm{I}_{1}$ (Fig. $2 \mathrm{~B}$ ). For eight PNs, the mean reversal potential (relative to rest) for $\mathrm{I}_{1}$ was $-13.1 \pm 0.5 \mathrm{mV}$ (mean \pm SEM), whereas the value for $\mathrm{I}_{2}$ was $-22.5 \pm 0.7 \mathrm{mV}$. Unlike $\mathrm{I}_{1}, \mathrm{I}_{2}$ was not blocked by bicuculline (see below), nor did this antagonist affect either the delayed EPSP that follows $I_{1}$ in PNs or the monosynaptic excitatory input to local interneurons (Fig. $1 B$ ). In PNs, the blockade of $\mathrm{I}_{1}$ by bicuculline resulted in marked desynchronization of the first PN spike in response to successive stimuli, but there were no spike failures, even with repetitive stimulation at $10 \mathrm{~Hz}$ (Fig. $1 B$ ). These findings point to different synaptic mechanisms for the three phases of the PN response and thus to a specific action of bicuculline on the receptors that mediate the fast early inhibitory phase, $\mathrm{I}_{1}$.

Although these results suggest that bicuculline specifically blocks GABA receptors that mediate $\mathrm{I}_{1}$, they do not rule out an action of bicuculline on other elements in the neural pathways converging on the PN. To demonstrate a direct effect of bicuculline on the GABA receptors of PNs, we used a microinjection system fitted with a multibarrel pressure pipette to introduce up 
A
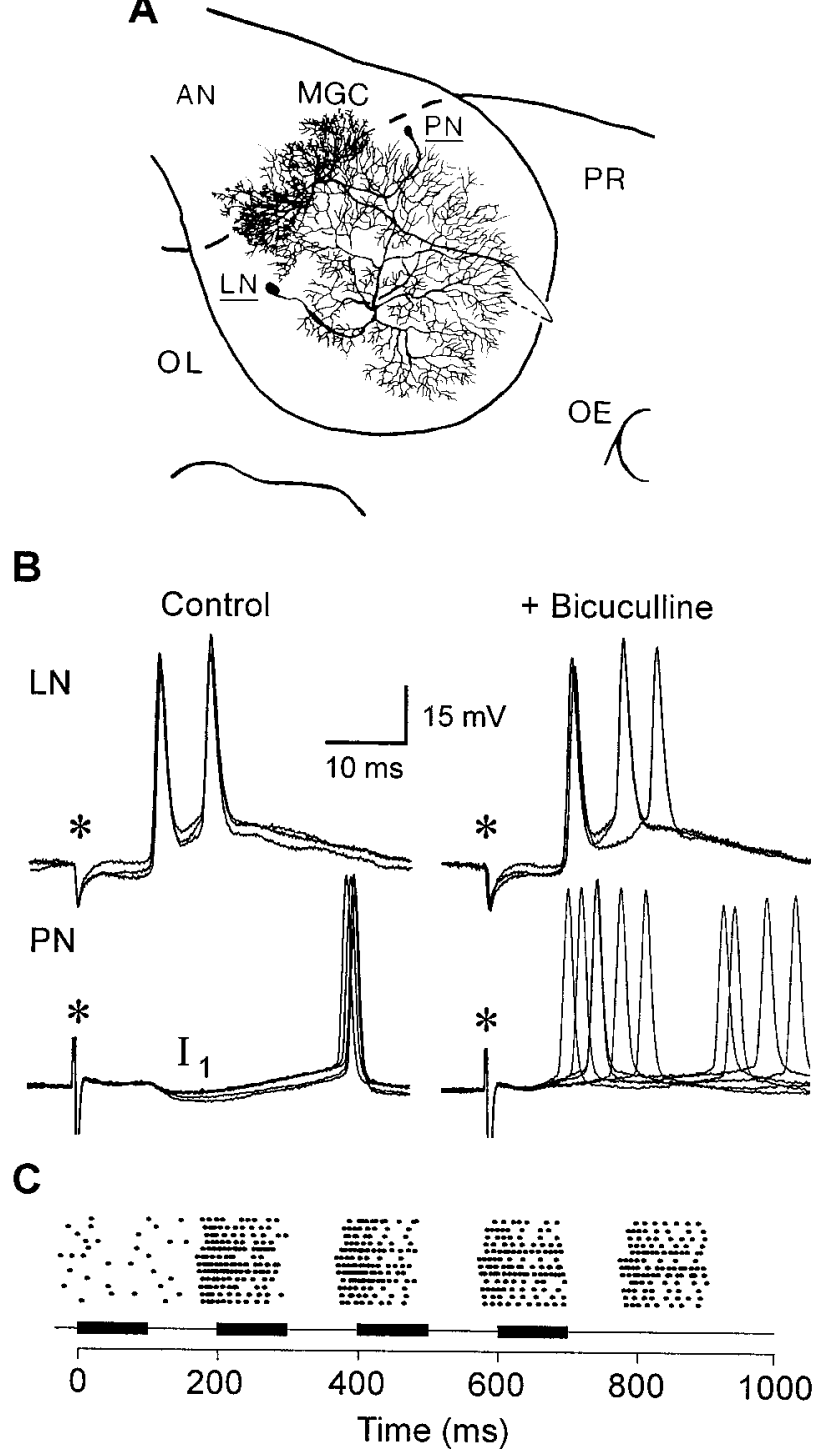

Figure 1. Local interneurons and projection neurons are the two main types of neurons involved in processing olfactory information in the glomeruli of the AL. Both cell types are readily identifiable in neuropil recordings, based on their differential responses to electrical stimulation of the antennal nerve and their distinctly different responses to treatment with GABA receptor antagonists. $A$, Serial reconstructions of one local interneuron $(L N)$ and one projection neuron $(P N)$ from two preparations, showing the overlap of their arborizations in the male-specific macroglomerular complex $(M G C)$. PNs with arborizations in the MGC respond selectively to the female sex pheromone (Hansson et al., 1991; Christensen et al., 1996). LNs are wide-field amacrine neurons that are confined to the AL and are mostly, if not exclusively, GABAergic. PNs have an axon that exits the lobe (dashed line) and terminates in higher centers in the protocerebrum $(P R)$. $A N$, Antennal nerve; $O E$, oesophageal canal; $O L$, optic lobe. $B$, Intracellular records illustrate the different postsynaptic responses evoked in an $L N$ (top records) and a PN (bottom records) by brief electrical stimulation of the ipsilateral AN (asterisks). Shock artifacts are clipped. Records on the left show responses in normal saline, and records on the right show the effects of the $\mathrm{GABA}_{\mathrm{A}}$ receptor antagonist bicuculline $(100 \mu \mathrm{M})$. Each record shows multiple consecutive sweeps using a stimulus pulse frequency of $10 \mathrm{~Hz}$. Under normal conditions, the LN exhibited a short-latency excitatory response that followed high-frequency stimulation, whereas the PN exhibited a multiphasic response with an early IPSP $\left(I_{1}\right)$ that became increasingly attenuated with successive stimulus pulses. Repetitive stimulation also led to a small reduction in the latency of the first spike in the $\mathrm{PN}$, but no such time shift was observed in the initial LN spike. A $10 \mathrm{~min}$ bath application of to seven different agents into the glomerular neuropil of the AL while simultaneously recording from a single PN with an intracellular microelectrode. With this system, we introduced pulses of GABA into the glomerular neuropil before and after application of bicuculline. Because bicuculline has been reported to antagonize cholinergic receptors in other insect preparations (Buckingham et al., 1994), and ACh is a putative transmitter of olfactory receptor cells in moths (Homberg et al., 1995, and references therein), the effects of bicuculline were also tested on pulses of ACh delivered into the glomerular neuropil.

\section{GABA mimics the early inhibitory phase of the $\mathrm{PN}$ response}

A brief pressure pulse of GABA (100 mM) delivered into the AL neuropil 100-200 $\mu \mathrm{m}$ from the recording electrode evoked a rapid membrane hyperpolarization, followed by complete cessation of background firing for many seconds (Fig. 3). This inhibitory response was robust and reproducible and was observed in 23 of 30 PNs tested. When the effects of several common agonists of GABA receptors were tested, these agents also revealed a specific pharmacological profile for the PN GABA receptor. The hyperpolarizing response of PNs to GABA application was mimicked by the $\mathrm{GABA}_{\mathrm{A}}$ receptor agonist muscimol $(n=5)$ but not by the $\operatorname{GABA}_{\mathrm{B}}$ agonist baclofen $(n=5)$ or by CACA $(n=5)$, an agonist used to characterize bicuculline- and baclofen-insensitive $\left(\mathrm{GABA}_{\mathrm{C}}\right.$ ) receptors (Fig. 3) (Woodward et al., 1993).

\section{Bicuculline blocks the inhibitory response to GABA but facilitates the excitatory response to $\mathrm{ACh}$}

The hyperpolarizing response to GABA was dose-dependent and in most cases was completely and reversibly abolished by a 100 msec pulse of bicuculline immediately preceding the GABA pulse (Fig. 4). In two cases in which GABA evoked a depolarizing response, pretreatment with bicuculline had no effect (Fig. 5). In sharp contrast, in 15 cases in which bicuculline was tested on hyperpolarizing GABA responses, the same pretreatment with the antagonist led to a $95 \%$ reduction in the response to a 100 msec pulse of GABA (Fig. 5). The effects of bicuculline were easily reversed after an interval of only a few minutes between trials. In eight cases in which ACh was tested in the same preparation with GABA, ACh evoked an excitatory response consisting of membrane depolarization and an increased rate of spiking activity (Figs. 4, 5). Unlike its antagonistic effect on GABA responses, a pulse of bicuculline preceding the ACh pulse did not block the excitatory response evoked by ACh. Instead, the ACh response was enhanced by pretreatment with bicuculline, resulting in almost a doubling of the mean rate of spike activity evoked by ACh alone $(191 \pm 11 \%$ of controls; $n=8)$ (Fig. 5$)$. In two

\section{$\leftarrow$}

bicuculline had no effect on the latency of the early spike response of the $\mathrm{LN}$, whereas the same treatment eliminated the $\mathrm{I}_{1}$ phase of the PN response, leading to a marked desynchronization and reduced latency of the PN spike. $C$, The responses of 12 PNs in as many males to short intermittent pulses of female sex pheromone illustrate how a time-varying odor stimulus modulates the temporal pattern of PN spike activity (stacked dot raster plots). The intermittent stimulus pattern shown here consisted of four $100 \mathrm{msec}$ pulses separated by $100 \mathrm{msec}$ intervals, and the timing of the voltage commands to the stimulus device are shown beneath the plots as a series of black bars. Each stimulus pulse evoked a train of spikes that was phase-locked to the intermittent stimulus pattern. Note too that the duration of every spike train copied the duration of the odor pulse, and that the temporal pattern of activity in each spike train is variable, both within and between cells, unlike the responses of PNs reported for other insect species (see Discussion). 


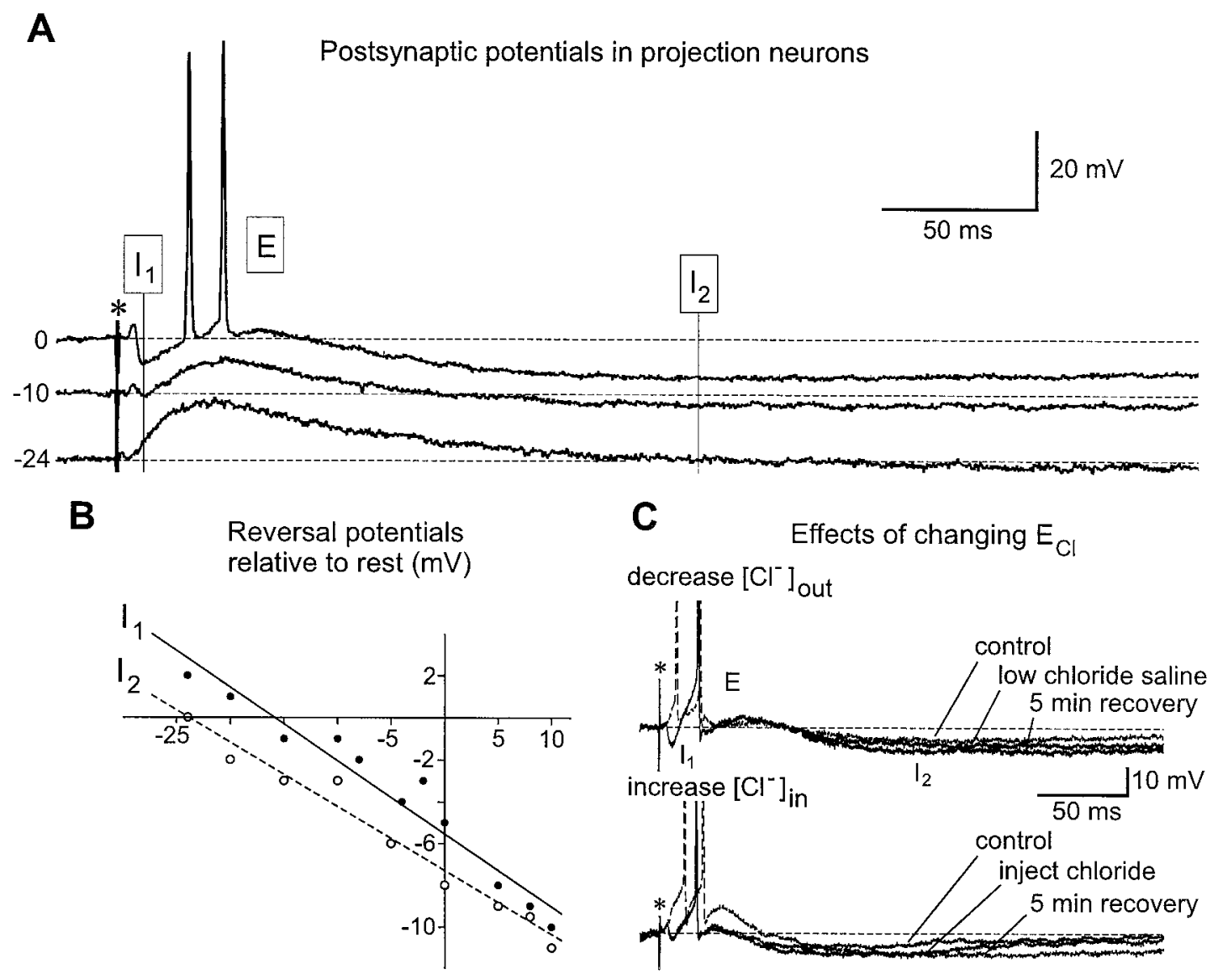

Figure 2. Effects of injected current and $\mathrm{Cl}^{-}$ion substitution on the postsynaptic potentials recorded in a moth PN. $A$, Electrical stimulation of the antennal nerve (asterisk) evoked the characteristic triphasic response in the PN, and each phase responded differently to a shift in the resting membrane potential. $B$, The two inhibitory phases $\left(I_{1}\right.$ and $\left.I_{2}\right)$ displayed distinctly different reversal potentials in response to injected current. Plots of IPSP amplitude versus membrane potential (relative to rest) reveal that the later relatively prolonged $\mathrm{I}_{2}$ phase of the PN response $(\bigcirc-O)$ had a reversal potential that was nearly $10 \mathrm{mV}$ more negative than that of the early fast $\mathrm{I}_{1}$ phase $\left(-C, \mathrm{I}_{1}\right.$ and $\mathrm{I}_{2}$ evoked by antennal nerve shock (asterisks) were affected differently by changes in the value of $E_{\mathrm{Cl}}$. Reducing extracellular chloride by substituting $18.7 \mathrm{mM} \mathrm{Na}_{2} \mathrm{SO}_{4}$ for $37.5 \mathrm{~mm} \mathrm{NaCl}$ (top records) or increasing intracellular chloride by passing hyperpolarizing current (bottom records) led to a decrease and reversal of $\mathrm{I}_{1}$, but not of $\mathrm{I}_{2}$ (broken traces). Either treatment caused $\mathrm{I}_{1}$ to become depolarizing, accompanied by increased excitability in the PN $(E)$. Effect in bottom records is shown immediately after current was discontinued. The effects of both treatments were highly reproducible and readily reversible after only a few minutes of recovery time. The $\mathrm{I}_{1}$ phase recovered fully after a return to normal saline solution for $5 \mathrm{~min}(t o p)$ or cessation of hyperpolarizing current for 5 min (bottom). Resting potential is indicated by dashed horizontal lines.

cases in which ACh evoked a hyperpolarizing response, bicuculline had no effect on the response of one PN and reduced the response of the other by $\sim 50 \%$ (Fig. 5).

\section{Bicuculline disrupts the temporal pattern of action potentials evoked by odor stimulation}

In PNs that give mixed inhibitory and excitatory responses to the blend of pheromone components (the so-called "blend neurons" of the MGC), the duration of the excitatory phase of the response to odor stimulation closely matches the duration of the stimulus from $\sim 50$ to $500 \mathrm{msec}$ (Christensen and Hildebrand, 1997). These PNs can report rapid changes in the temporal pattern of pheromonal stimuli striking the antenna. It is not known, however, how these neurons respond to prolonged stimulation in which the antenna is exposed to a continuous stream of odor of duration $>500 \mathrm{msec}$. Such sustained stimuli are used in studies of the responses of olfactory networks in several other insect species in which prolonged stimulation with odor evokes dynamic patterns of firing, often far outlasting the stimulus itself (Sun et al., 1993; Laurent, 1996; Joerges et al., 1997). We investigated the re- sponses of MGC blend neurons in M. sexta under similar conditions of prolonged stimulation.

As shown in Figure 6, when the antenna was stimulated with a $300 \mathrm{msec}$ pulse of pheromone (the species-specific blend), the burst of spikes evoked in the blend neuron matched the duration of the stimulus (305 $\pm 7 \mathrm{msec}$ ) (Christensen and Hildebrand, 1997) and reached a maximum instantaneous frequency of $129 \pm$ $10 \mathrm{impulses} / \mathrm{sec}(n=11)$. After the stimulus-linked response, the neuron abruptly hyperpolarized, and spiking ceased. With longer stimuli, however, the responses of blend neurons became qualitatively different and temporally complex. With a continuous $1 \mathrm{sec}$ stimulus, the initial phase of the response was comparable to that evoked by the $300 \mathrm{msec}$ stimulus (burst duration, $303 \pm 5 \mathrm{msec}$; maximum instantaneous frequency, $133 \pm 11$ impulses/sec; $n=11)$. Under maintained stimulation, however, the membrane repolarized and produced a second burst of action potentials. The end of the stimulus was marked by a pronounced membrane hyperpolarization that persisted for several seconds as the membrane gradually returned to its resting state. As the stimulus 


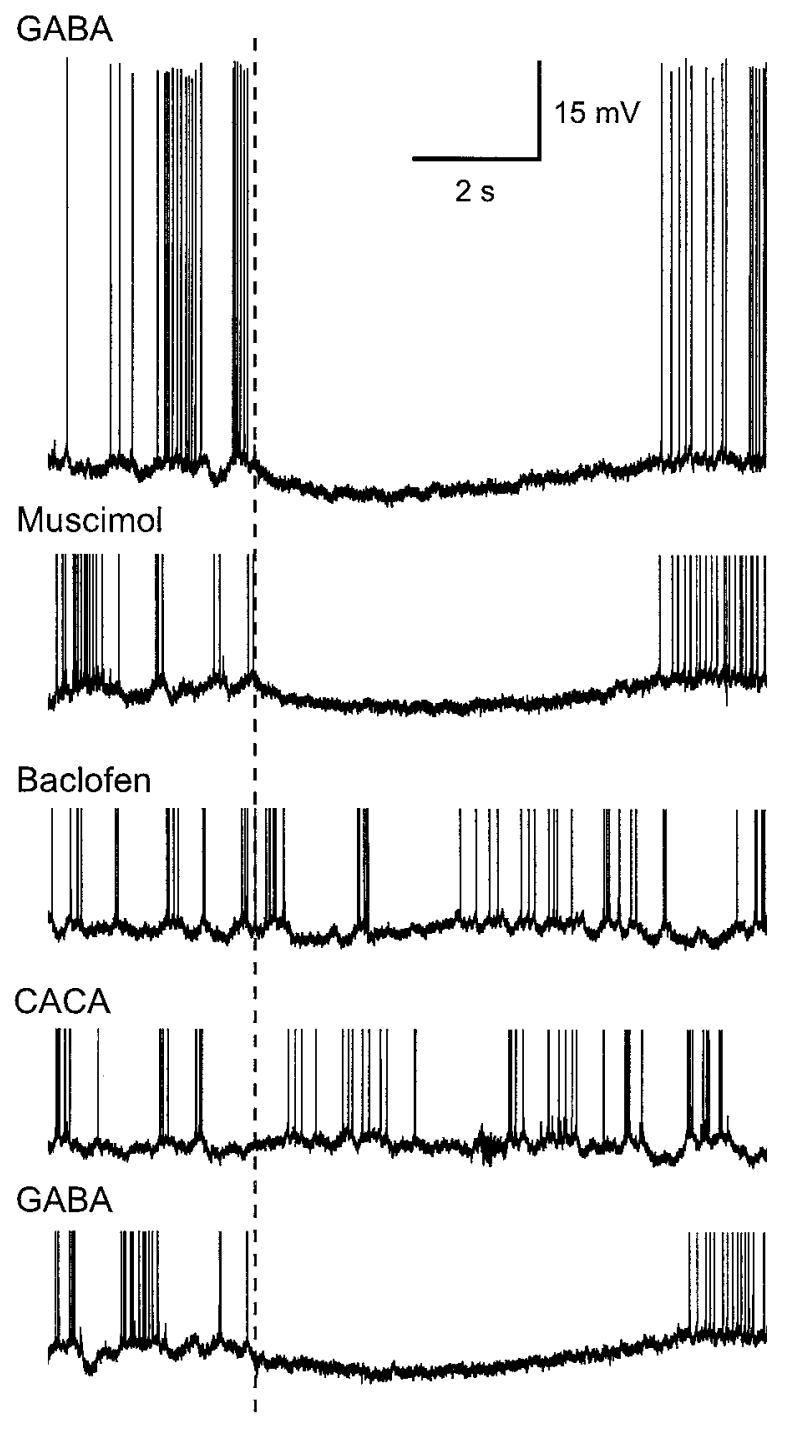

Figure 3. Intracellular responses of a PN to pressure ejection of GABA and several GABA receptor agonists (at $100 \mathrm{~mm}$ ) into the antennal lobe neuropil. A brief $(50 \mathrm{msec})$ GABA pulse evoked a rapid onset and prolonged hyperpolarization in the $\mathrm{PN}$ that could prevent spiking for $>10$

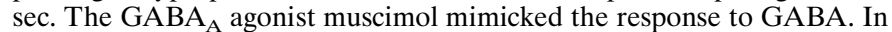
contrast, baclofen, a potent $\mathrm{GABA}_{\mathrm{B}}$ agonist, evoked only a very small and delayed membrane hyperpolarization, whereas cis-4-aminocrotonic acid $(C A C A)$, a potent $\mathrm{GABA}_{\mathrm{C}}$ agonist, had no detectable effect. Onset of the pressure pulse is indicated by the dashed vertical line through the records. Spikes in all but the top record are clipped.

duration was increased further, the responses of these blend neurons became more and more oscillatory $(n=11)$ (Fig. 6). The evoked oscillations were observed only with such extended stimuli, and more cycles were observed as stimulus duration was increased. Blend neurons fired action potentials only during a few cycles of the evoked oscillation, and the cycles that were correlated with firing were not the same from trial to trial in a given neuron (Fig. 6). The precise temporal sequence of firing was not the same for each stimulus pulse but became more temporally complex with increasing stimulus duration. The end of the sequence was punctuated by pronounced membrane hyperpolarization, which ensured that each sequence also reflected the duration of the stimulus. This hyperpolarization slowly decayed over several seconds before the membrane returned to its prestimulated state.
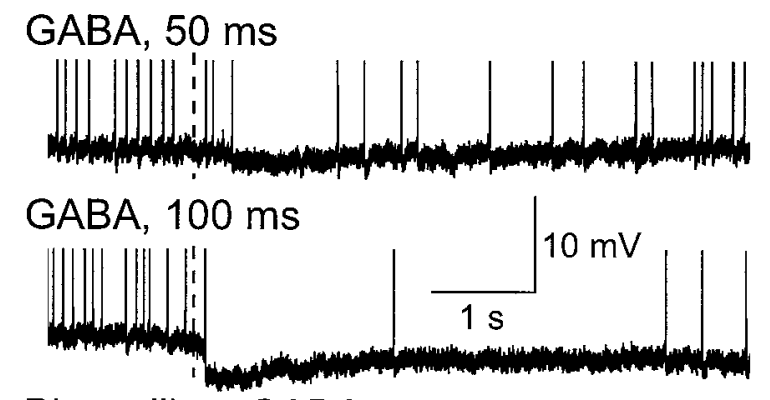

Bicuculline, GABA

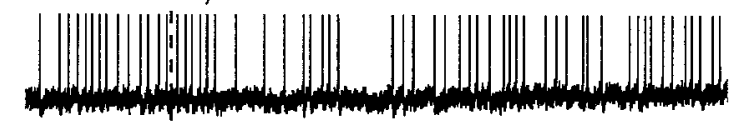

GABA only

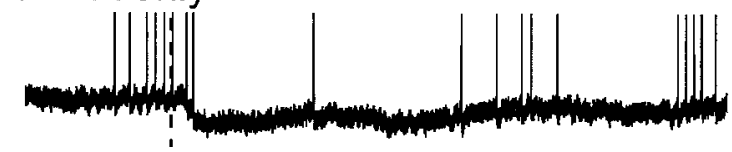

ACh, $100 \mathrm{~ms}$

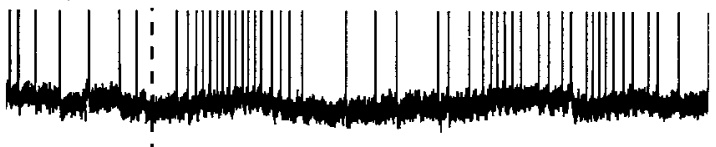

Bicuculline, ACh

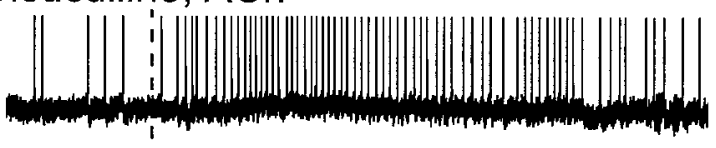

ACh only

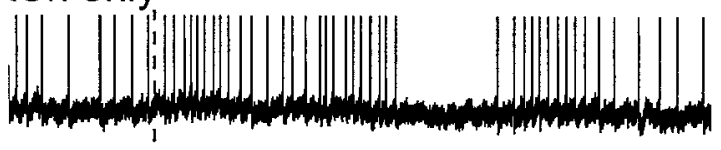

Figure 4. Comparison of intracellular PN responses to applied GABA and $\mathrm{ACh}$ (both at $100 \mathrm{~mm}$ ) and the effect of pretreatment with bicuculline $(100 \mu \mathrm{M})$ pressure ejected into the neuropil. Onset of transmitter pulse is indicated by the dashed vertical line through the records. Pressure ejection of GABA evoked rapid, prolonged, and dose-dependent membrane hyperpolarization. A $100 \mathrm{msec}$ pulse of bicuculline immediately preceding a $100 \mathrm{msec}$ pulse of GABA completely and reversibly abolished the GABAevoked hyperpolarization. In contrast to GABA, a $100 \mathrm{msec}$ pulse of ACh evoked a membrane depolarization and increased spiking activity. Pretreatment with bicuculline did not block, but instead led to a marked facilitation of, the excitatory response to ACh. The responses to GABA and $\mathrm{ACh}$ were reproducible and reversible. Spikes in all records are clipped.

Rhythmic response patterns such as those shown in Figure 6 could be evoked by more than one regimen of stimuli. As shown above, these patterns resulted from prolonged stimulation, but discontinuous stimulation with the same odor blend evoked responses that were time-locked to the patterned stimuli (Figs. $1 C$, 7) (Christensen and Hildebrand, 1997). With either stimulation scheme, these rhythmic spiking patterns in blend neurons were completely disrupted by treatment with bicuculline. A rhythmic pattern produced by five discrete pulses of a pheromonal stimulus was transformed by bicuculline treatment into a tonic burst of spikes that could no longer encode the temporal pattern of the pulsatile input (Fig. 7A). The later hyperpolarizing phase of the response $\left(\mathrm{I}_{2}\right)$, however, was not abolished by bicuculline, and the membrane hyperpolarized after the last stimulus pulse. In response to a single $5 \mathrm{sec}$ exposure of the antenna to the same 


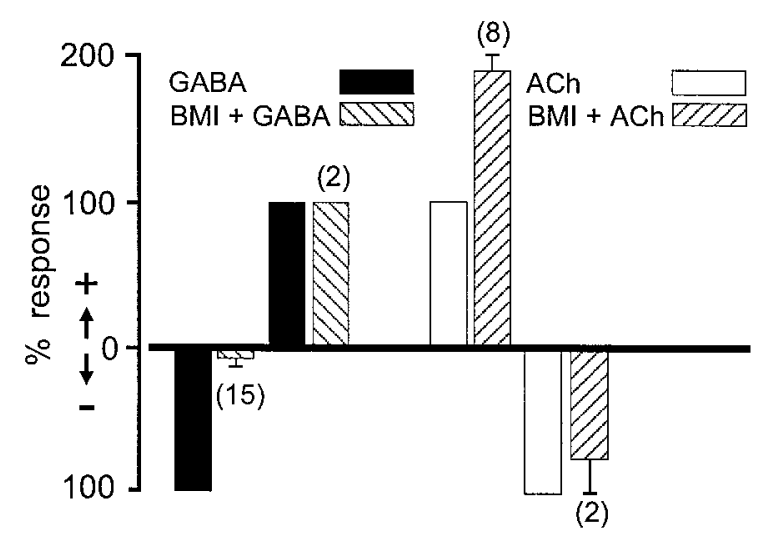

Figure 5. Summary of responses to GABA and ACh and the effects of pretreatment with $100 \mu \mathrm{M}$ BMI. For both transmitters, amplitude of evoked membrane hyperpolarization was used as a measure of inhibitory responses, and number of evoked spikes above background was used as a measure of excitatory responses. In the majority of cases, responses to GABA were inhibitory and blocked by BMI, whereas responses to ACh were excitatory and facilitated by BMI. Numbers in parentheses are replicates, and all data are mean \pm SEM.

pheromonal stimulus, however, the blend neuron exhibited oscillatory activity with a temporal pattern very different from that produced by the pulsatile stimulus described above (Fig. $7 B$ ). This oscillatory response was also completely disrupted by bicuculline, in the presence of which the extended pheromonal stimulus evoked tonic firing that persisted throughout the stimulation period. Again, the later $\mathrm{I}_{2}$ phase of the response was not affected by bicuculline. Experiments using the same stimulation protocol to test four additional blend-selective PNs confirmed that the facilitating effects of bicuculline were reproducible and readily reversible.

\section{DISCUSSION}

\section{Pharmacology of a GABA receptor in moth olfactory PNs}

We are now beginning to understand the pharmacology of the GABA receptors that mediate the fast early IPSP $\left(\mathrm{I}_{1}\right)$ in moth olfactory PNs. The properties of these receptors appear to be more like those of the classical vertebrate $\mathrm{GABA}_{\mathrm{A}}$ receptors than those reported for other arthropod GABA receptors (see below) (Hosie et al., 1997). Bicuculline, a potent antagonist of vertebrate $\mathrm{GABA}_{\mathrm{A}}$ receptors, including receptors apparently on the dendrites of vertebrate mitral/tufted cells (Duchamp-Viret, 1993; Duchamp-Viret and Duchamp, 1993), is also a potent antagonist of $\mathrm{I}_{1}$ in moth olfactory PNs (Waldrop et al., 1987). Bicuculline reversibly blocks $I_{1}$ after only a few minutes of exposure but leaves the EPSP and $\mathrm{I}_{2}$ phase of the response intact. Removal of the shunting effect of the $\mathrm{Cl}^{-}$conductance underlying $\mathrm{I}_{1}$ leads to a marked increase in the depolarizing phase of the PN response, along with increased excitability (Figs. $1 B, 2 C, 4$ ). Thus, regulation of these receptors is a key to controlling the output from the glomerulus.

Unlike their vertebrate counterparts, which probably use glutamate as the primary excitatory transmitter at synapses between olfactory receptor-cell axons and mitral/tufted cells (Trombley and Shepherd, 1993; van den Pol, 1995), olfactory receptor neurons in insects appear to use ACh (Waldrop and Hildebrand, 1989; Homberg et al., 1995). In this regard, it is important to note that bicuculline has been shown to block certain nicotinic ACh

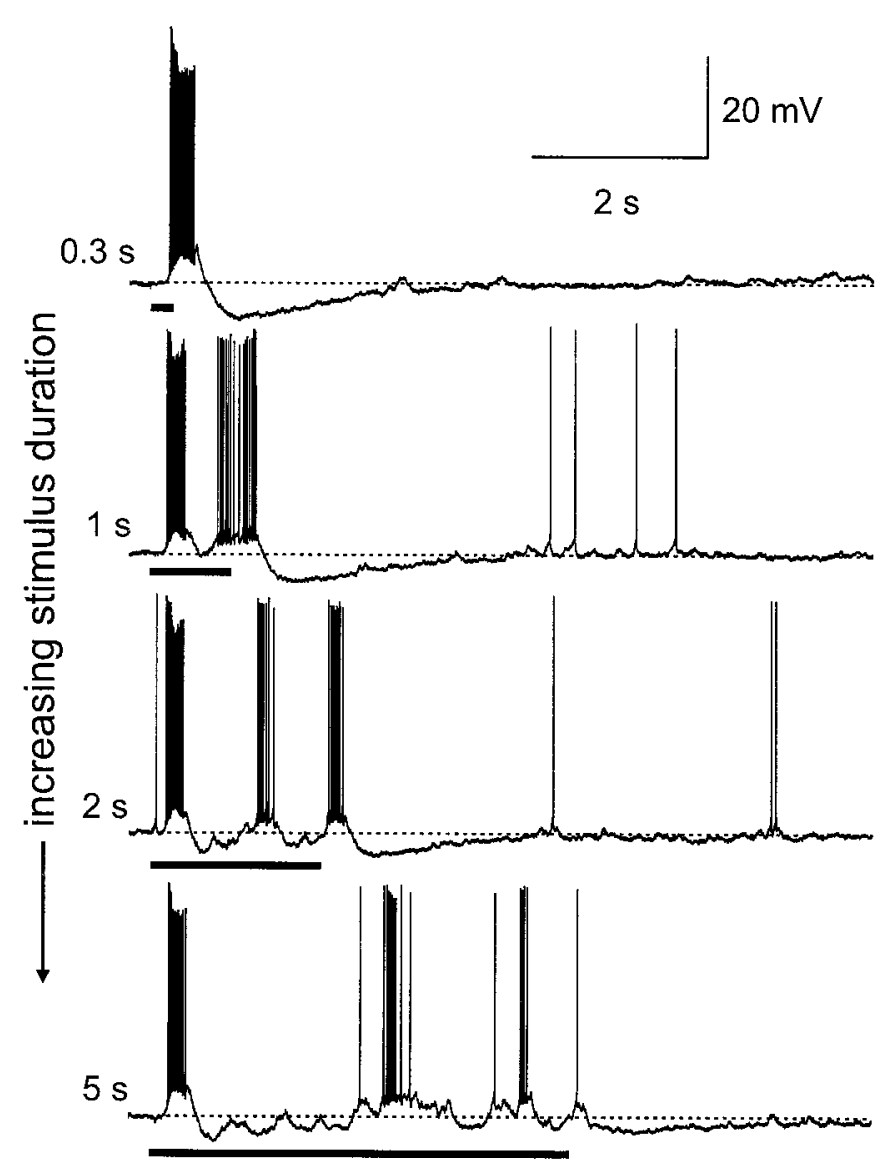

Figure 6. Temporal pattern of action potentials in response to a single odor pulse was strongly dependent on the duration of the odor pulse, and this pattern increased in complexity as the stimulus duration increased. Stimulus is the species-specific sex pheromone blend (stimulus pulses indicated by bar beneath each record). A relatively brief 300 msec odor pulse evoked a train of spikes that lasted for $309 \mathrm{msec}$ before being abruptly halted by a strong membrane hyperpolarization. As the stimulus duration was lengthened from 1 to 2 to $5 \mathrm{sec}$, each successive pulse evoked a greater number of alternating inhibitory and excitatory potentials, and the response of PNs became increasingly oscillatory. These oscillations could be a consequence of extensive synaptic interconnection with GABAergic LNs in the antennal lobe and suggest the emergence of a different computational mechanism with prolonged stimulation.

receptors in insects (Buckingham et al., 1994), perhaps reflecting the highly conserved subunit composition of $\mathrm{GABA}_{\mathrm{A}}$ and $\mathrm{ACh}$ receptors (Macdonald and Olsen, 1994; McKernan and Whiting, 1996). Thus, the effects of bicuculline injected into the glomerular neuropil in vivo might be attributable to blockade of ACh receptors rather than GABA receptors (Buckingham et al., 1994). We tested this hypothesis by measuring responses to injected GABA and $\mathrm{ACh}$ and then examining the effects of pretreatment with bicuculline on these responses. We found that a pulse of injected bicuculline preceding a GABA pulse eliminated the hyperpolarization evoked by GABA but did not antagonize the depolarization evoked by ACh. In fact, bicuculline significantly facilitated the depolarization evoked by ACh, leading to a substantial increase in the rate of spike activity (Figs. 4, 5). One plausible explanation for this effect is that in vivo, ACh released by primary afferent axons activates parallel excitatory and inhibitory pathways that converge on the PN (Fig. 8). When ACh is applied alone, these two inputs are integrated and balanced in the PN, resulting in a net reduction in the overall response. In the pres- 
A

\section{2-Hz pulsed stimulation}
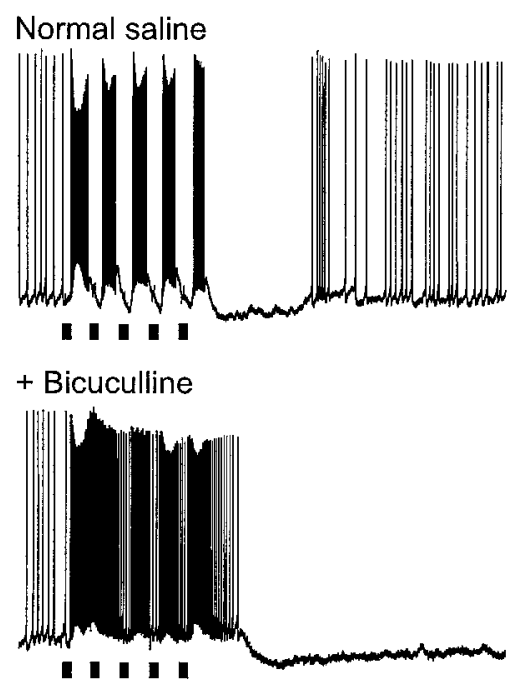

wash $10^{\prime}$

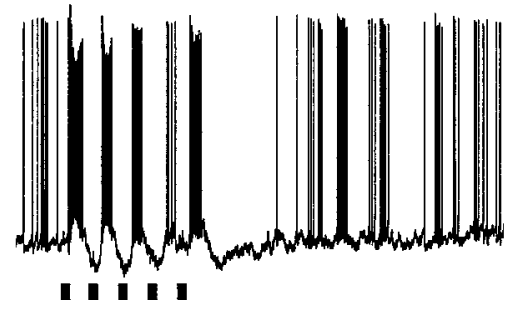

B

\section{5-second continuous stimulation}
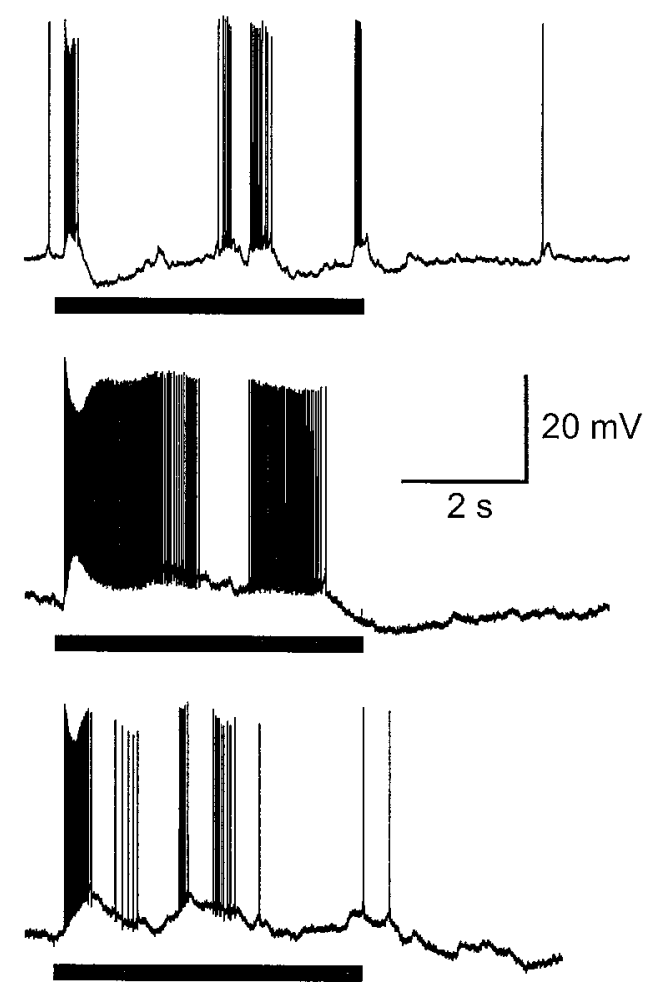

Figure 7. Temporal response to odor also depended on the temporal pattern of input to the PN. $A$, Responses to stimulation with a series of five $100 \mathrm{msec}$ odor pulses at 500 msec intervals. Intermittent stimulation evoked a discrete burst of spikes for each pulse (top trace). This temporal pattern was completely disrupted after bath application of $100 \mu \mathrm{M}$ bicuculline for $5 \mathrm{~min}$ (middle trace). Blocking the fast GABA-mediated chloride conductance in the PN revealed the underlying excitatory input to the neuron, as indicated by increased tonic spiking activity. Note, however, that the slower later hyperpolarizing phase that signals the end of the response was delayed but not blocked by bicuculline. The stimulusmodulated spike pattern returned after a switch back to normal saline solution for 10 min (bottom trace). B, Responses in the same PN to a single $500 \mathrm{msec}$ pulse show that the same stimulus could evoke a different temporal pattern of activity in the PN (top trace). In this case, the initial burst of spikes was followed by a series of periodic fluctuations in membrane potential accompanied by irregular spiking activity. The membrane fluctuations and temporal spiking pattern were eliminated by bicuculline (middle trace). Again, this effect was readily reversible; a temporally patterned response returned after washout (bottom trace), but the temporal pattern of action potentials was not the same as that before bicuculline treatment.

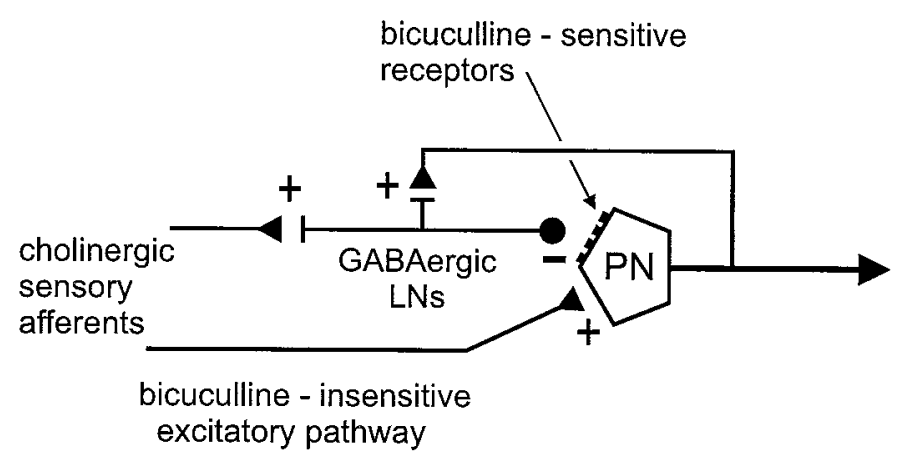

Figure 8. Model of two opposing parallel pathways converging on a glomerular PN based on the current pharmacological, anatomical, and electrophysiological data. Two feedforward pathways and one feedback pathway to the PN are shown, but others yet to be characterized may exist. According to this model, bicuculline blocks the inhibitory input to the PN, mediated through the population of GABAergic local interneurons $(L N s)$ (only one shown). Bicuculline blocks both the short-latency IPSP generated by feedforward inhibition (Fig. $1 B$ ) and the slow oscillations (Fig. 7B) possibly generated by a feedback pathway to the same pool of inhibitory LNs. Output synapses that could mediate this effect have been identified in PNs. Bicuculline does not block the excitatory input pathway $(+)$, however, regardless of whether the PN receives direct input from primary afferent axons (as shown) or indirect input through other intercalated neurons. The fact that $I_{1}$ always precedes the excitation in these PNs is additional evidence for an indirect excitatory input.

ence of bicuculline, however, the GABA-mediated inhibitory input is blocked, leaving the excitatory input to dominate the response. Thus, in the moth olfactory system, bicuculline appears to be a potent antagonist of a $\mathrm{GABA}_{\mathrm{A}}$-type receptor but not of cholinergic receptors. Our evidence therefore suggests that the subunit composition of the $\mathrm{GABA}_{\mathrm{A}}$ receptor on moth PNs, particularly the low-affinity bicuculline-binding site, is distinct from that of other reportedly bicuculline-insensitive insect GABA receptors (Sattelle, 1990; ffrench-Constant, 1994; Waldrop, 1994; Hosie et al., 1997). As further evidence of this, the response to GABA application is mimicked by the $\mathrm{GABA}_{\mathrm{A}}$-receptor agonist muscimol but not by the $\mathrm{GABA}_{\mathrm{B}}$ agonist baclofen or by cis-4aminocrotonic acid, a probe used for bicuculline- and baclofeninsensitive $\left(\mathrm{GABA}_{\mathrm{C}}\right)$ receptors (Fig. 3) (Woodward et al., 1993).

Timing of PN responses is not odor-specific, and different temporal patterns of the same stimulus evoke two distinct flight behaviors

We have shown that in certain olfactory PNs, which are involved in central processing of sex-pheromonal information in male moths, the response to continuous stimulation varies with stimulus duration and is distinctly different from the stimulus-locked responses to pulses of odor. These results suggest that a qualitatively different message is relayed by PNs to higher centers in the protocerebrum under conditions of prolonged and intermittent odor exposure (Figs. 6, 7) (Christensen and Hildebrand, 1997). A sustained pheromonal stimulus (longer than $\sim 500 \mathrm{msec}$ ) results in a temporally dynamic pattern of spiking (Figs. $6,7 B$ ), and this oscillatory activity is completely disrupted by bicuculline, with the result that the PN remains tonically depolarized throughout the response sequence (Fig. $7 B$ ). This finding indicates that the slow oscillations of membrane potential that develop under conditions of prolonged stimulation could result from feedback to the GABAergic local interneurons that synaptically inhibit the PNs (Fig. 8). In support of this model, output synapses that could 
mediate recurrent inhibition of PNs have been identified in several species (Malun, 1991; Leitch and Laurent, 1996; Distler and Boeckh, 1997; Sun et al., 1997). According to this view, GABA release, and thus the shunting of excitatory currents in the PN, would be periodic, resulting in transient impulse initiation during the positive phase of the oscillation cycles, as shown in Figures 6 and $7 B$.

There is abundant evidence from a variety of moth species that the temporal pattern of a sex-pheromonal stimulus is important in determining the male's behavior. Intermittent stimulation with sex pheromone is necessary for sustained upwind flight (Kennedy et al., 1980, 1981; Willis and Baker, 1984; Baker et al., 1985) or walking (Kramer, 1992; Kanzaki, 1997) toward a pheromone source, but flying moths cease to make upwind progress and instead begin to "cast" or counterturn across the wind line when exposed to a prolonged pheromonal stimulus (Kennedy et al., 1980, 1981; Willis and Baker, 1984; Baker et al., 1985; Baker and Haynes, 1989). Males that have temporarily lost a pheromone plume they have been tracking (owing, for example, to a shift in wind direction) also enter into casting behavior, which often helps them regain contact with the plume. Thus, judging from their behavior, continuous exposure of male moths to sex pheromone is operationally equivalent to experiencing an odor-free environment. We hypothesize that the slow oscillatory response of PNs to prolonged odor stimulation might help synchronize periodic neural output from the MGC and therefore could be involved in driving or modulating the temporal regularity of casting behavior that is expressed under this particular stimulus condition. The slow periodic PN response evoked by prolonged odor stimulation could therefore be interpreted by higher centers as representing a stimulus condition different from intermittent stimulation with the same odor. Female moths flying in a plume of host plant odor also exhibit casting behavior after having lost the plume in a shifting wind field or under conditions of continuous stimulation (Haynes and Baker, 1989; Willis and Arbas, 1991). This pattern of behavior and the neural mechanisms that underlie it are therefore not unique to males or to pheromonal information processing in the brain.

\section{Two coding schemes in one neuron}

Our findings suggest that insect PNs could use different coding schemes to discriminate between persistent and intermittent stimulation with the same odor. When the stimulus is intermittent and the pulse durations are short, the PNs can effectively track even random pulses (Fig. 7A) (Christensen and Hildebrand, 1997), and these neurons and other PNs use a rate code to report concentration changes (Christensen and Hildebrand, 1987; Kanzaki et al., 1989; Hildebrand and Shepherd, 1997). When the signal is more uniform and prolonged, however, the GABAergic LNs that synaptically influence PNs (and each other) in the glomerular neuropil could also contribute to oscillatory activity underlying a temporal code (Figs. 6, 7B). In other insects, 20-35 $\mathrm{Hz}$ oscillations have been shown recently to underlie synchrony among subsets of AL neurons in response to prolonged odor stimulation (Laurent, 1996), and similar rapid oscillations in the local field potential have been observed in the pheromoneprocessing MGC in M. sexta (Heinbockel et al., 1998). It has been suggested that a given odor may be represented in the AL by a unique dynamical pattern of activity across a spatially distributed population of PNs, but it is not known whether these patterns would persist under more naturally intermittent stimulus conditions.
In moth PNs, oscillations emerge only as a consequence of prolonged odor stimulation at pulse durations above $\sim 500 \mathrm{msec}$. Under intermittent stimulus conditions, the slow periodic hyperpolarization of the PN membrane does not have time to develop, owing to the renewed excitatory drive evoked by each successive odor pulse. The temporal pattern of the response therefore reflects the temporal pattern of the input, thus maximizing the amount of information available for higher processing (Fig. 7A) (Christensen and Hildebrand, 1997). Indeed, recent studies using vertebrates and invertebrates have stressed the importance of using more natural dynamic stimuli in assessing the ability of neural circuits to encode environmental stimuli, because spiking neurons can transmit information about changing stimuli more efficiently than continuous stimuli (Mainen and Sejnowski, 1995; de Ruyter van Steveninck et al., 1997). In some situations, however, prolonged stimulation is unavoidable. In this context, the precise temporal pattern of the response could be used in encoding some other aspect of the odor, possibly even its chemical identity (Laurent, 1996). In the case of moths, however, continuous olfactory stimulation causes both males and females to abort goal-oriented upwind flight, and thus this context evokes a qualitatively different perception than does pulsatile stimulation with the same odor.

The responses of PNs of moth and locust ALs to prolonged stimulation (even with very different odors) are remarkably alike, yet despite these similarities, bicuculline-sensitive GABA receptors like those of moth PNs apparently are absent in locust PNs (MacLeod and Laurent, 1996). The GABA receptor antagonist picrotoxin, which readily disrupts odor responses in moth PNs (Waldrop et al., 1987), does not influence the temporal pattern of spiking in other insect PNs but does block the populationsynchronizing oscillations (MacLeod and Laurent, 1996; Stopfer et al., 1997). Our findings therefore suggest that the separation of mechanisms governing neuronal oscillations and temporal patterning of spiking activity, as found in locusts (MacLeod and Laurent, 1996) and honeybees (Stopfer et al., 1997), is not common to all insects.

In summary, our findings are consistent with the hypothesis that olfactory glomeruli are multifunctional coding modules in the primary olfactory center of the brain. The core of this hypothesis is that each glomerulus processes more information than simply the molecular features of the odor stimulus. Specifically, some PNs can also encode how the stimulus changes with time, and this information is used by the animal to help locate the odor source. Our new findings suggest an added level of complexity in these information-processing circuits by showing that single PNs may use different coding schemes that are appropriate to different environmental contexts.

\section{REFERENCES}

Adrian ED (1942) Olfactory reactions in the brain of the hedgehog. J Physiol (Lond) 100:459-473.

Adrian ED (1950) The electrical activity of the mammalian olfactory bulb. Electroencephalogr Clin Neurophysiol 2:377-388.

Atema J (1995) Chemical signals in the marine environment: dispersal, detection, and temporal signal analysis. Proc Natl Acad Sci USA 92:62-66.

Axel R (1995) The molecular logic of smell. Sci Am 273:154-159.

Baker TC, Haynes KF (1989) Field and laboratory electroantennographic measurements of pheromone plume structure correlated with oriental fruit moth behaviour. Physiol Entomol 14:1-12.

Baker TC, Willis MA, Haynes KF, Phelan PL (1985) A pulsed cloud of pheromone elicits upwind flight in male moths. Physiol Entomol 10:257-265. 
Buck LB (1996) Information coding in the vertebrate olfactory system. Annu Rev Neurosci 19:517-544.

Buckingham SD, Hue B, Sattelle DB (1994) Actions of bicuculline on cell body and neuropilar membranes of identified insect neurones. $\mathbf{J}$ Exp Biol 186:235-244.

Bullock TH (1997) Signals and signs in the nervous system: the dynamic anatomy of electrical activity is probably information-rich. Proc Natl Acad Sci USA 94:1-6.

Cardé RT, Minks AK (1997) Insect pheromone research: new directions. New York: Chapman and Hall.

Christensen TA, Hildebrand JG (1987) Male-specific, sex pheromoneselective projection neurons in the antennal lobes of the moth Manduca sexta. J Comp Physiol [A] 160:553-569.

Christensen TA, Hildebrand JG (1997) Coincident stimulation with pheromone components improves temporal pattern resolution in central olfactory neurons. J Neurophysiol 77:775-781.

Christensen TA, Waldrop BR, Harrow ID, Hildebrand JG (1993) Local interneurons and information processing in the olfactory glomeruli of the moth Manduca sexta. J Comp Physiol [A] 173:385-399.

Christensen TA, Heinbockel T, Hildebrand JG (1996) Olfactory information processing in the brain: encoding chemical and temporal features of odors. J Neurobiol 30:82-91.

Christensen TA, Waldrop BR, Hildebrand JG (1998) GABAergic mechanisms that shape the temporal response to odors in moth olfactory projection neurons. Ann NY Acad Sci, in press.

de Ruyter van Steveninck RR, Lewen GD, Strong SP, Koberle R, Bialek W (1997) Reproducibility and variability in neural spike trains. Science 275:1805-1808.

Dethier VG (1987) Sniff, flick, and pulse: an appreciation of interruption. Proc Am Philos Soc 131:159-176.

Distler P (1990) GABA-immunohistochemistry as a label for identifying local interneurons and their synaptic contacts in the antennal lobes of the American cockroach. Histochemistry 93:617-626.

Distler P, Boeckh J (1997) Synaptic connections between identified neuron types in the antennal lobe glomeruli of the cockroach, Periplaneta americana. J Comp Neurol 378:307-319.

Duchamp-Viret P (1993) GABAergic control of odor-induced activity in the frog olfactory bulb: electrophysiological study with picrotoxin and bicuculline. Neuroscience 53:111-120.

Duchamp-Viret P, Duchamp A (1993) GABAergic control of odorinduced activity in the frog olfactory bulb: possible GABAergic modulation of granule cell inhibitory action. Neuroscience 56:905-914.

ffrench-Constant RH (1994) The molecular and population genetics of cyclodiene insecticide resistance. Insect Biochem Mol Biol 24:335-345.

Gelperin A, Kleinfeld D, Denk W, Cooke IRC (1996) Oscillations and gaseous oxides in invertebrate olfaction. J Neurobiol 30:110-122.

Haberly LB (1985) Neuronal circuitry in olfactory cortex: anatomy and functional implications. Chem Senses 10:219-238.

Hamilton KA, Kauer JS (1989) Patterns of intracellular potentials in salamander mitral/tufted cells in response to odor stimulation. J Neurophysiol 62:609-625.

Hansson BS, Christensen TA, Hildebrand JG (1991) Functionally distinct subdivisions of the macroglomerular complex in the antennal lobe of the male sphinx moth Manduca sexta. J Comp Neurol 312:264-278.

Haynes KF, Baker TC (1989) An analysis of anemotactic flight in female moths stimulated by host odour and comparison with the males' response to sex pheromone. Physiol Entomol 14:279-289.

Heinbockel T, Kloppenburg P, Hildebrand JG (1998) Pheromoneevoked potentials and oscillations in the antennal lobes of the sphinx moth Manduca sexta. J Comp Physiol [A], in press.

Hildebrand JG, Shepherd GM (1997) Mechanisms of olfactory discrimination: converging evidence for common principles across phyla. Annu Rev Neurosci 20:595-631.

Homberg U (1990) Immunocytochemical demonstration of transmitter candidates in the central olfactory pathways in the sphinx moth Manduca sexta. In: Olfaction and taste X (Døving KB, ed), pp 151-158. Oslo: Graphic Communication Systems.

Homberg U, Hoskins SG, Hildebrand JG (1995) Distribution of acetylcholinesterase activity in the deutocerebrum of the sphinx moth Manduca sexta. Cell Tissue Res 279:249-259.

Hopfield JJ (1996) Transforming neural computations and representing time. Proc Natl Acad Sci USA 93:15440-15444.

Hosie AM, Aronstein K, Sattelle DB, ffrench-Constant RH (1997) Molecular biology of insect neuronal GABA receptors. Trends Neurosci 20:578-583.
Hoskins SG, Homberg U, Kingan TG, Christensen TA, Hildebrand JG (1986) Immunocytochemistry of GABA in the antennal lobes of the sphinx moth Manduca sexta. Cell Tissue Res 244:243-252.

Joerges J, Küttner A, Galizia CG, Menzel R (1997) Representations of odours and odour mixtures visualized in the honeybee brain. Nature 387:285-288.

Kanzaki R (1997) Pheromone processing in the lateral accessory lobes of the moth brain: flip-flopping signals related to zigzagging upwind walking. In: Insect pheromone research: new directions (Cardé RT, Minks AK, eds), pp 291-303. New York: Chapman and Hall.

Kanzaki R, Arbas EA, Strausfeld NJ, Hildebrand JG (1989) Physiology and morphology of projection neurons in the antennal lobe of the male moth Manduca sexta. J Comp Physiol [A] 165:427-453.

Kennedy JS, Ludlow AR, Sanders CJ (1980) Guidance system used in moth sex attraction. Nature 295:475-477.

Kennedy JS, Ludlow AR, Sanders CJ (1981) Guidance of flying male moths by wind-borne sex pheromone. Physiol Entomol 6:395-412.

King JR, Christensen TA, Hildebrand JG (1997) Host-plant odor processing by projection neurons in the antennal lobe of female moths, Manduca sexta. Soc Neurosci Abstr 23:1828.

König P, Engel AK, Singer W (1996) Integrator or coincidence detector? The role of the cortical neuron revisited. Trends Neurosci 19:130-136.

Kramer E (1992) Attractivity of pheromone surpassed by time-patterned application of two nonpheromone compounds. J Insect Behav 5:83-97.

Laurent G (1996) Dynamical representation of odors by oscillating and evolving neural assemblies. Trends Neurosci 19:489-496.

Leitch B, Laurent G (1996) GABAergic synapses in the antennal lobe and mushroom body of the locust olfactory system. J Comp Neurol 372:487-514.

Macdonald RL, Olsen RW (1994) GABA A receptor channels. Annu Rev Neurosci 17:569-602.

MacLeod K, Laurent G (1996) Distinct mechanisms for synchronization and temporal patterning of odor-encoding neural assemblies. Science 274:976-979.

Mafra-Neto A, Cardé RT (1994) Fine-scale structure of pheromone plumes modulates upwind orientation of flying moths. Nature 369:142-144.

Mainen ZF, Sejnowski TJ (1995) Reliability of spike timing in neocortical neurons. Science 268:1503-1506.

Malun D (1991) Synaptic relationship between GABA-immunoreactive neurons and an identified uniglomerular projection neuron in the antennal lobe of Periplaneta americana: a double labeling electron microscopic study. Histochemistry 96:197-207.

McKernan RM, Whiting PJ (1996) Which GABA $_{\mathrm{A}}$-receptor subtypes really occur in the brain? Trends Neurosci 19:139-143.

Mombaerts P, Wang F, Dulac C, Chao SK, Nemes A, Mendelsohn M, Edmondson J, Axel R (1996) Visualizing an olfactory sensory map. Cell 87:675-686.

Moore PA (1994) A model of the role of adaptation and disadaptation in olfactory receptor neurons. Chem Senses 19:71-86.

Mori K, Yoshihara Y (1995) Molecular recognition and olfactory processing in the mammalian olfactory system. Prog Neurobiol 45:585-619.

Murlis J (1997) Odor plumes and the signal they provide. In: Insect pheromone research: new directions (Cardé RT, Minks AK, eds), pp 221-231. New York: Chapman and Hall.

Sattelle DB (1990) GABA receptors of insects. Adv Insect Physiol 22:1-13.

Selchow KI, Christensen TA, Oland LA, Hildebrand JG (1997) Neural processing of plant-associated odors in the antennal lobe of the moth, Manduca sexta. Chem Senses 22:790.

Stopfer M, Bhagavan S, Smith BH, Laurent G (1997) Impaired odour discrimination on desynchronization of odour-encoding neural assemblies. Nature 390:70-74

Sun XJ, Fonta C, Masson C (1993) Odour quality processing by bee antennal lobe interneurones. Chem Senses 18:355-377.

Sun XJ, Tolbert LP, Hildebrand JG (1997) Synaptic organization of the uniglomerular projection neurons of the antennal lobe of the moth Manduca sexta: a laser scanning confocal and electron microscopic study. J Comp Neurol 379:2-20.

Trombley PQ, Shepherd GM (1993) Synaptic transmission and modulation in the olfactory bulb. Curr Opin Neurobiol 3:540-547.

Tumlinson JH, Brennan MM, Doolittle RE, Mitchell ER, Brabham A, Mazomenos BE, Baumhover AH, Jackson DM (1989) Identification 
of a pheromone blend attractive to Manduca sexta $(L)$ males in a wind tunnel. Arch Insect Biochem Physiol 10:255-271.

van den Pol AN (1995) Presynaptic metabotropic glutamate receptors in adult and developing neurons: autoexcitation in the olfactory bulb. J Comp Neurol 359:253-271.

Vickers NJ, Baker TC (1992) Male Heliothis virescens sustain upwind flight in response to experimentally pulsed filaments of their sex pheromone. J Insect Behav 5:669-687.

Vickers NJ, Baker TC (1994) Reiterative responses to single strands of odor promote sustained upwind flight and odor source location by moths. Proc Natl Acad Sci USA 91:5756-5760.

Waldrop B (1994) Physiological and pharmacological properties of responses to GABA and ACh by abdominal motor neurons in Manduca sexta. J Comp Physiol [A] 174:775-785.

Waldrop B, Hildebrand JG (1989) Physiology and pharmacology of acetylcholinergic responses of interneurons in the antennal lobes of the moth Manduca sexta. J Comp Physiol [A] 164:433-441.

Waldrop B, Christensen TA, Hildebrand JG (1987) GABA-mediated synaptic inhibition of projection neurons in the antennal lobes of the sphinx moth, Manduca sexta. J Comp Physiol [A] 161:23-32.

Wellis DP, Scott JW, Harrison TA (1989) Discrimination among odorants by single neurons in the rat olfactory bulb. J Neurophysiol 61:1161-1177.

Willis MA, Arbas EA (1991) Odor-modulated upwind flight of the sphinx moth, Manduca sexta. J Comp Physiol [A] 169:427-440.

Willis MA, Baker TC (1984) Effects of intermittent and continuous pheromone stimulation on the flight behaviour of the oriental fruit moth, Grapholita molesta. Physiol Entomol 9:341-358.

Woodward RM, Polenzani L, Miledi R (1993) Characterization of bicuculline/baclofen-insensitive ( $\rho$-like) $\gamma$-aminobutyric acid receptors expressed in Xenopus oocytes. II. Pharmacology of $\gamma$-aminobutyric acid $\mathrm{A}$ and $\gamma$-aminobutyric acid B receptor agonists and antagonists. Mol Pharmacol 43:609-625.

Youngentob SL, Mozell MM, Sheehe PR, Hornung DE (1987) A quantitative analysis of sniffing strategies in rats performing odor detection tasks. Physiol Behav 41:59-69. 